\title{
Brittle compressive failure of salt-water columnar ice under biaxial loading
}

\author{
T. R. SMITH* AND E. M. SCHULSON \\ Thayer School of Engineering, Dartmouth College, Hanover, New Hampshire 03755, U.S.A.
}

\begin{abstract}
The brittle failure of saline columnar ice was investigated under biaxial compression at $\dot{\epsilon}=10^{-2} \mathrm{~s}^{-1}$ and $-10^{\circ}$ and $-40^{\circ} \mathrm{C}$, over the range $0 \leq R_{\mathrm{A}}<1$ where $R_{\mathrm{A}}$ is the ratio of the intermediate to major principal compressive stress. The major principal stress and the intermediate (confining) stress were orthogonal to the columnar axes (type-A confinement); both stresses and the $c$-axes of the grains were co-planar. The results confirm earlier work by Hausler (1981) and Timco and Frederking $(1983,1986)$ on saline ice and follow similar behavior to fresh-water columnar ice found by Smith and Schulson (1993) and Frederking (1977). Failure stress and failure mode are sensitive to the confinement and two regimes of behavior are found: the failure stress first rapidly increases with $R_{\mathrm{A}}$ in the range $0 \leq R_{\mathrm{A}}<R_{\mathrm{t}}$ and then tends to decrease for $R_{\mathrm{A}}>R_{\mathrm{t}}$. The transition stress ratio, $R_{\mathrm{t}}$, changes from $\approx 0.2$ at $-10^{\circ} \mathrm{C}$ to $\approx 0.1$ at $-40^{\circ} \mathrm{C}$. The failure mode changes from axial splitting to shear faulting in the loading plane for $0<R_{\mathrm{A}}<R_{\mathrm{t}}$. Above $R_{\mathrm{t}}$, failure changes to a combined mode of splitting across the columns and shear faulting out of the loading plane. The failure-stress envelope is of a truncated Coulomb-type. Damage studies show wing cracks and local fragmentation of grains involving the brine pockets. The results are explained in terms of Coulombic sliding and Hertzian crack mechanics.
\end{abstract}

\section{INTRODUCTION}

The compressive strength of salt-water ice is important for many Arctic development activities. The strength depends on many factors including temperature, deformation rate, microstructure and stress state. Concerning the last factor, the effect of confinement on the mechanical properties of saline columnar ice has been reported several times (e.g. Häusler, 1981; Timco and Frederking, 1983; Cox and others, 1984, 1985; RichterMenge and others, 1986; Sammonds and others, 1989; Murrell and others, 1991). The generally accepted view is that the failure stress increases quite sharply upon increasing the confinement. For the most part, however, the work to date concentrates on the lower strain-rate behavior where the ice is so-called ductile and on behavior near to the ductile-to-brittle transition.

For the case of biaxial loading, the studies of Häusler (1981) and Timco and Frederking (1983, 1986) show important trends when the ice is loaded orthogonal to the long axes of the columnar grains. Häusler (1981) reported the ductile compressive strength of saline ice at $\dot{\epsilon}=2 \times$ $10^{-4} \mathrm{~s}^{-1}$ at $-10^{\circ} \mathrm{C}$ under fully biaxial loading (i.e. $\sigma_{1}=$ $\left.\sigma_{2}\right)$. It was found that failure stress increases to about 4 times the uniaxial value when both stresses are perpendi-

\footnotetext{
* Present address: Institute for Mechanics and Materials, University of California - San Diego, La Jolla, CA 92093, U.S.A.
}

cular to the columns (type-A confinement), whereas, for confinement parallel to the columns (type-B), the failure stress is unchanged. Timco and Frederking $(1983,1986)$ obtained similar results for plane-strain biaxial compressive loading of saline ice over the strain-rate range of $10^{-}$ ${ }^{5} \mathrm{~s}^{-1}-10^{-3} \mathrm{~s}^{-1}$. They found that, under rigid type-A confinement, the failure stress increases in a ratedependent way, from about 4 times the uniaxial value at a low strain rate $\left(\dot{\epsilon}=10^{-5} \mathrm{~s}^{-1}\right)$ to about 2 times at a higher rate $\left(\dot{\epsilon}=10^{-3} \mathrm{~s}^{-1}\right)$. This behavior is also similar to that observed during an earlier study by Frederking (1977) on the coaxial compressive strength of fresh-water columnar ice under the same type of confinement.

This paper focuses on brittle behavior and on the effect of type-A confinement on the biaxial failure of columnar saline ice. The work follows an earlier study by Smith and Schulson (1993) on columnar fresh-water ice and notes similarities and differences in the behavior of the materials. The overall objective is to help to elucidate the failure mechanisms. This work is part of a larger study by Smith (1991) on the effect of stress state on the brittle compressive failure of columnar ice.

\section{EXPERIMENTAL PROCEDURE}

\subsection{The material}

Laboratory-grown, salt-water columnar ice was made using the procedure of Kuehn and others (1990). The ice 
was uni-directionally grown as a large "puck", as described by Smith and Schulson (1993), from salt water. The water was prepared by dissolving solid salts found in sea water into filtered Hanover tap water to a concentration of 29 ppt by weight (see Table 1).

Table 1. Salt-water ice properties

$\begin{array}{lll}\text { Property This study Reference } & \end{array}$

$\begin{array}{ccc}\begin{array}{c}\text { Density } \\ \left(\mathrm{Mg} \mathrm{m}^{-3}\right)\end{array} & 0.909 \pm 0.0005 & 0.914 \pm 0.003 \\ \text { (Kuehn and others, 1990) }\end{array}$

\# The commercial product "Instant Ocean" (Aquarium Systems, Mentor, Ohio) was used which contains by weight: $\mathrm{Cl}^{-}, 47 \% ; \mathrm{Na}^{+}, 26 \% ; \mathrm{SO}_{4}{ }^{2-}, 6.5 \% ; \mathrm{Mg}^{2+}$, $3.2 \% ; \mathrm{Ca}^{2+}, 1.1 \%$. $\mathrm{K}^{+}, 1.0 \% ; \mathrm{HCO}_{3}{ }^{-}, 0.49 \% ; \mathrm{BO}_{3}{ }^{-}$, $0.14 \% ; \mathrm{Sr}^{2+}, 0.03 \%, \mathrm{H}_{2} \mathrm{O}, 14.4 \%$.

* Determined by weighing in air and in iso-octane at $-10^{\circ} \mathrm{C}$.

${ }^{\dagger}$ Calculated following the procedure of Cox and Weeks (1982).

¥ Calculated from the measured conductivity of sample meltwater at $23^{\circ} \mathrm{C}$.

Samples were examined by thin section $(<1 \mathrm{~mm}$ thick) under cross-polarized illumination following the procedure of Langway (1958) to determine the microstructural characteristics. The grain-size varied from $3.2 \mathrm{~mm}$ near the upper surface of the puck to $8.6 \mathrm{~mm}$ near the lower surface, with an average value of $5.4 \pm 1.2 \mathrm{~mm}$. These sizes were measured perpendicular to the long-columnar axes by the linear-intercept method. The majority of the $c$-axes of the grains were oriented horizontally with respect to the growth direction (within $\approx 15^{\circ}$ ) and with no preferred alignment within the horizontal plane. The ice was similar to S2 first-year sea ice (Table 1).

\subsection{Specimens}

The top $75 \mathrm{~mm}$ and bottom $25 \mathrm{~mm}$ parts of the parent ice puck were discarded. Samples were rough cut and then milled to prismatic plates and cubes (plates: $155 \times 155 \times 25 \mathrm{~mm}^{3}$; cubes: $\left.155 \times 155 \times 155 \mathrm{~mm}^{3}\right)$. Tolerances of better than $6.5 \times 10^{-4} \mathrm{rad}(<0.1 \mathrm{~mm}$ deviation from parallel sides) were achieved. The specimens were made such that two pairs of faces were parallel to the axes of the columnar grains and one pair normal to them. Plates were cut such that the columnar axes ran through the thickness. The sample sizes ensured that a minimum of 25 grains was included across the width. As with the fresh-water ice tests of Smith and Schulson (1993), several "micro-similar" sets of plates, which contain essentially the same grains, were made.

\subsection{Testing procedures}

Compression experiments were performed under both uniaxial and biaxial loading at temperatures of $-10^{\circ}$ and $-40^{\circ} \mathrm{C}\left( \pm 0.2^{\circ} \mathrm{C}\right)$ using equipment and procedures described by Smith and Schulson (1993). Loadingplaten displacement was measured by two clip gauges per axis, mounted on opposite sides of the sample. Brushtype loading platens, which have been shown to produce reliable results, were used following Smith and Schulson (1993).

All tests were performed at a constant nominal strain rate of $\dot{\epsilon} \approx 10^{-2} \mathrm{~s}^{-1}$, along the axis of the major principal stress (Fig. 1). The largest principal stress $\left(\sigma_{1}\right)$ and the intermediate principal stress $\left(\sigma_{2}\right)$ were coplanar with the $c$ axes of the grains and orthogonal to the columnar axes

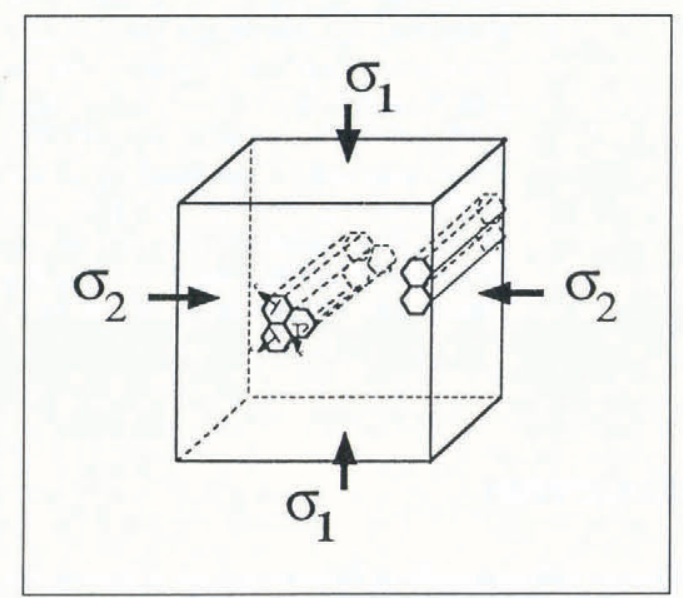

Fig. 1. Schematic sketch showing orientations of the major $\left(\sigma_{1}\right)$ and the minor $\left(\sigma_{2}\right)$ stresses with respect to the columnar grains. The loading configuration approximates plane-strain conditions.

(type-A confinement); the smallest principal stress was zero. We use the nomenclature major stress and confining stress to denote $\sigma_{1}$ and $\sigma_{2}$, respectively. The stress state was specified in terms of the ratio, $R_{\mathrm{A}}=\sigma_{2} / \sigma_{1}$.

To examine the evolution of the failure process, several specimens were tested using pulsed loading. This procedure consisted of loading at a constant strain rate $\left(\dot{\epsilon} \approx 10^{-2} \mathrm{~s}^{-1}\right)$ and constant $R_{\mathrm{A}}$, to set stress level and rapidly unloading. After a pulse, the damage induced in the form of cracking was evaluated by thin section. Pulsed-load experiments were performed for $R_{\mathrm{A}}=0$ and 0.15 .

\section{EXPERIMENTAL RESULTS}

All samples showed brittle behavior independent of test temperature and specimen shape. Failure occurred suddenly, by macroscopic splitting or shear faulting. A typical stress-strain plot is shown in Figure 2. 


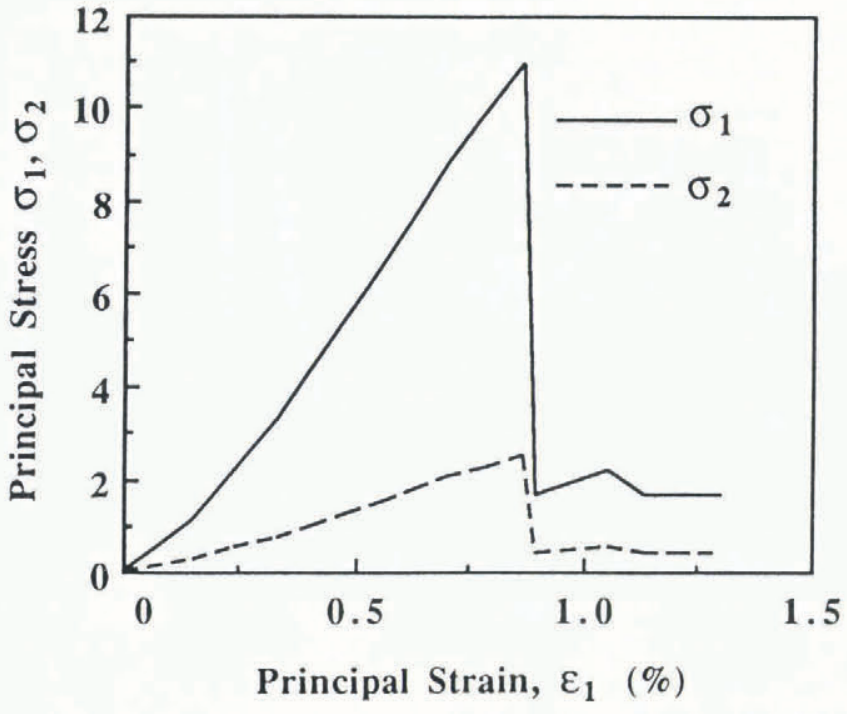

Fig. 2. Typical stress-strain plot for salt-water ice loaded normal to the columns $\left(R_{\mathrm{A}}=0.23\right)$. Axial strains calculated from platen displacements, measured on either side of the specimens.

\subsection{Failure stress}

Figure 3 plots the largest stress at failure, $\sigma_{1 \mathrm{f}}$, versus $R_{\mathrm{A}}$; different symbols denote failure modes, discussed below. At both temperatures, the data are scattered, which is a characteristic of brittle compressive failure. Yet, two regimes of behavior are evident. Under lower biaxial confinement (regime 1), the failure stress $\sigma_{1 \mathrm{f}}$ increases rapidly with a small increase in $R_{\mathrm{A}}$; under higher biaxial confinement (regime 2), $\sigma_{1 \mathrm{f}}$ decreases with increasing $R_{\mathrm{A}}$. The transition between the two regimes occurs at $R_{\mathrm{t}} \approx 0.2$ at $-10^{\circ} \mathrm{C}$ and at $R_{\mathrm{t}} \approx 0.1$ at $-40^{\circ} \mathrm{C}$. The change in slope upon exceeding $R_{\mathrm{t}}$ suggests a change in failure mechanism, which will be discussed below. This same two-stage behavior under type-A confinement is seen in the biaxial compressive behavior of fresh-water ice (Smith and Schulson, 1993). Figure 3 also shows that, within the scatter, the strength of the plates and cubes is similar; thus, the shape of the specimen is not considered to be an important factor.

\subsection{Brittle-failure envelope}

Figure 4 shows the brittle-failure envelopes in a principal stress plane. The data are the same as in Figure 3 but plotted twice to illustrate better the shape of the envelope (i.e. it is symmetric about the line $\sigma_{1}=\sigma_{2}$ ). Data from both plate and cube samples are used; different symbols denote failure modes. To a first approximation, the envelope at both temperatures can be described by a polygon. In the compressive quadrant at low $\sigma_{2}$ (regime 1), the behavior can be approximated by a Coulomb-type relationship of the form:

$$
\sigma_{\mathrm{lf}}=\sigma_{\mathrm{U}}+k_{1} \sigma_{2}
$$

where $\sigma_{\mathrm{U}}$ is the uniaxial compressive failure stress and $k_{1}$ is a temperature-dependent constant. At higher $\sigma_{2}$ (regime 2), the behavior shows a different relationship, of the form:

$$
\sigma_{1 \mathrm{f}}=k_{2}-\sigma_{2}
$$

where $k_{2}$ is a different constant. The polygon is completed by extending the regime 1 relationship into the compression-tension quadrants until a tension cut-off truncates the envelope at the uniaxial tensile strength of $\approx 1.0 \mathrm{MPa}$, measured normal to the long axis of the columns (Dykins, 1966; Kuehn and others, 1990). Table 2 lists values for the parameters in Equations (1) and (2).

Alternate biaxial failure envelopes in the literature for saline ice are the anisotropic plasticity surfaces used by Häusler (1983) and the $n$-type plasticity failure surface of Timco and Frederking (1986). These surfaces are based on saline-ice data obtained at $\dot{\epsilon}=2 \times 10^{-4} \mathrm{~s}^{-1}$ and $-10^{\circ} \mathrm{C}$, where the ice is ductile. Both envelopes are

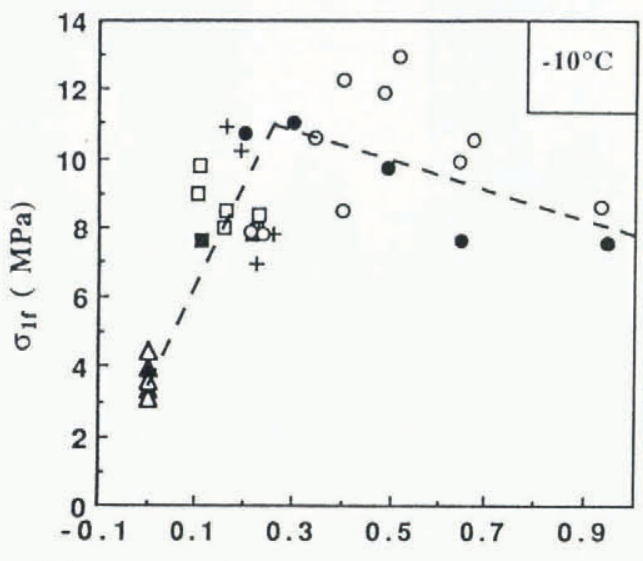

(a)

$$
\text { Stress Ratio, } R_{A}
$$

\begin{tabular}{|c|c|c|}
\hline \multicolumn{3}{|c|}{ Failure Modes } \\
\hline 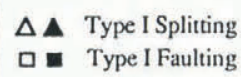 & + & $\begin{array}{l}\text { Type I Faulting and Type II Faulting } \\
\text { Type II Faulting and Type II Splitting }\end{array}$ \\
\hline
\end{tabular}

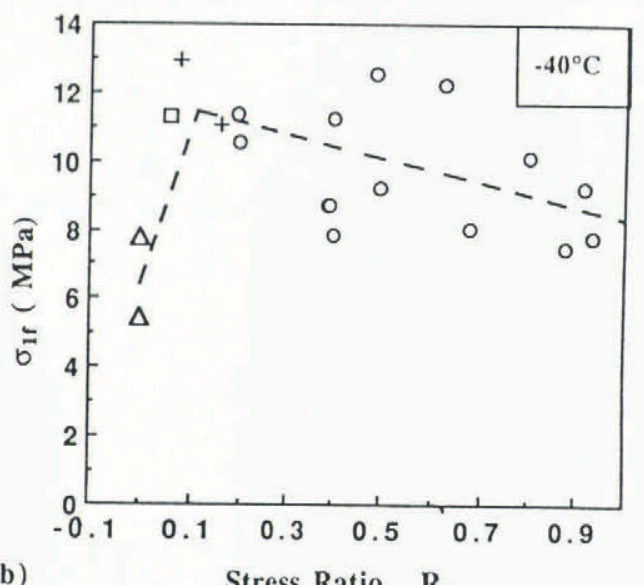

Fig. 3. Failure stress versus $R_{\mathrm{A}}=\sigma_{2} / \sigma_{1}$ for salt-water ice loaded normal to the columns; (a) $-10^{\circ} \mathrm{C},(\mathrm{b})-40^{\circ} \mathrm{C}$. Note two regimes of behavior of $\sigma_{1 \mathrm{f}}$ with $R_{\mathrm{A}}$, shown by dashed lines. 

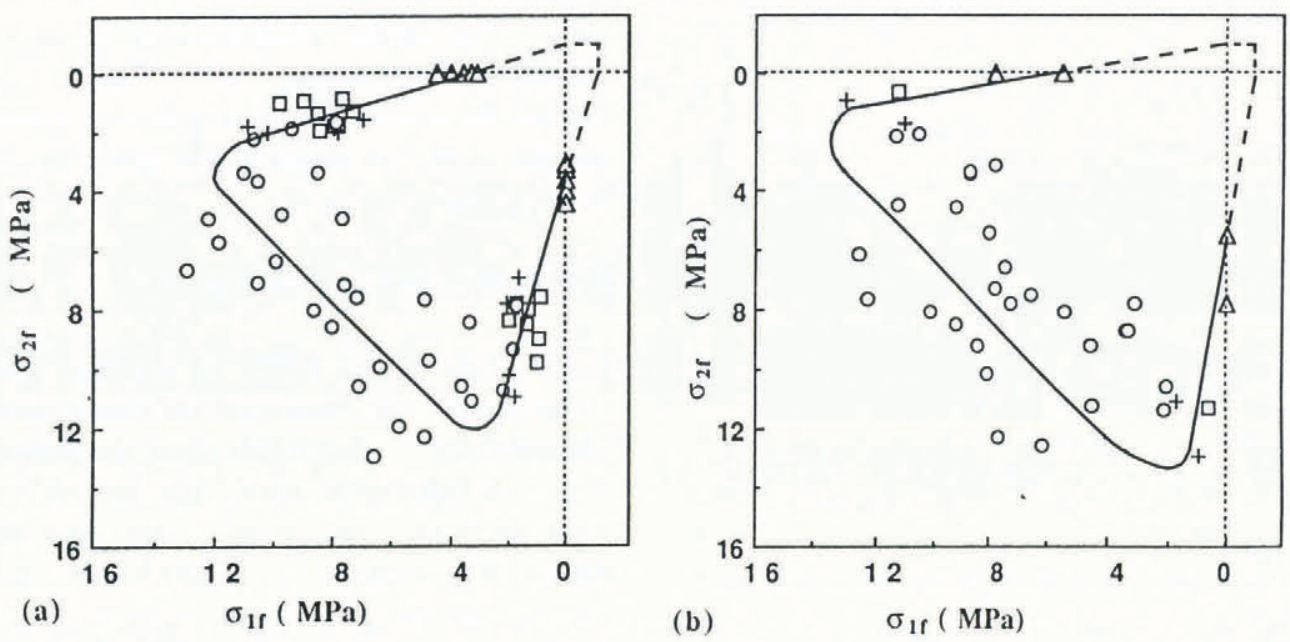

\begin{tabular}{|cccc|}
\hline \multicolumn{4}{|c|}{ Failure Modes } \\
\hline$\Delta$ & Type I Splitting & + & Type I Faulting and Type II Faulting \\
$\square$ & Type I Faulting & $\circ$ & Type II Faulting and Type II Splitting \\
\hline
\end{tabular}

Fig. 4. Brittle compressive failure envelopes (solid lines) for salt-water ice loaded normal to the axes of the columns; (a) $-10^{\circ} \mathrm{C}$, (b) $-40^{\circ} \mathrm{C}$.

Table 2. Values for $k_{1}$ and $k_{2}$

$\begin{array}{cccc}T & \sigma_{\mathrm{U}} & k_{1} & k_{2} \\ { }^{\circ} \mathrm{C} & \mathrm{MPa} & & \mathrm{MPa}\end{array}$

$\begin{array}{llll}-10 & 3.5 & 3.1 & 16 \\ -40 & 6.5 & 4.8 & 16\end{array}$

elliptical in shape in the $\sigma_{1}, \sigma_{2}$ plane but the Timco and Frederking envelope is truncated (i.e. has an abrupt change in slope) at the line $\sigma_{1}+\sigma_{2}=14.7 \mathrm{MPa}$ to fit the data better. While this type of approach could be used here, there is no physical basis for the fit and it is not clear that such a treatment is appropriate for data obtained in the brittle regime. Using a mechanistic approach presented in the discussion below, the simple linear expressions presented here for the failure envelope can be seen in a physical light and these provide an equivalent fit to the data.
The brittle-failure envelope is substantially different from the modified $n$-type surface of Timco and Frederking (1986) for saline columnar ice at $-2^{\circ} \mathrm{C}$, where the ice is ductile. This difference is not surprising, as brittle behavior might be expected to show a different sensitivity to confinement.

It is interesting to note that the salt-water envelope is almost identical to the fresh-water envelope noted elsewhere (Smith and Schulson, 1993). This implies similar failure mechanisms in the two materials.

\subsection{Macroscopic failure modes}

Three dominant failure modes were seen, depending on the loading ratio, $R_{\mathrm{A}}$. They are type I splitting, type I faulting and a combination type II faulting/type II splitting, described below. These modes are shown schematically in Figure 5; the first two are in the plane of loading and the combination failure is out-of-plane. At the transition between in-plane and out-of-plane failures (i.e. $R_{\mathrm{A}}=R_{\mathrm{t}}$ ), a combination type $\mathrm{I} /$ type II faulting was also observed.

Under zero confinement, failure occurred by axial splitting and localized fragmentation of the ice near the

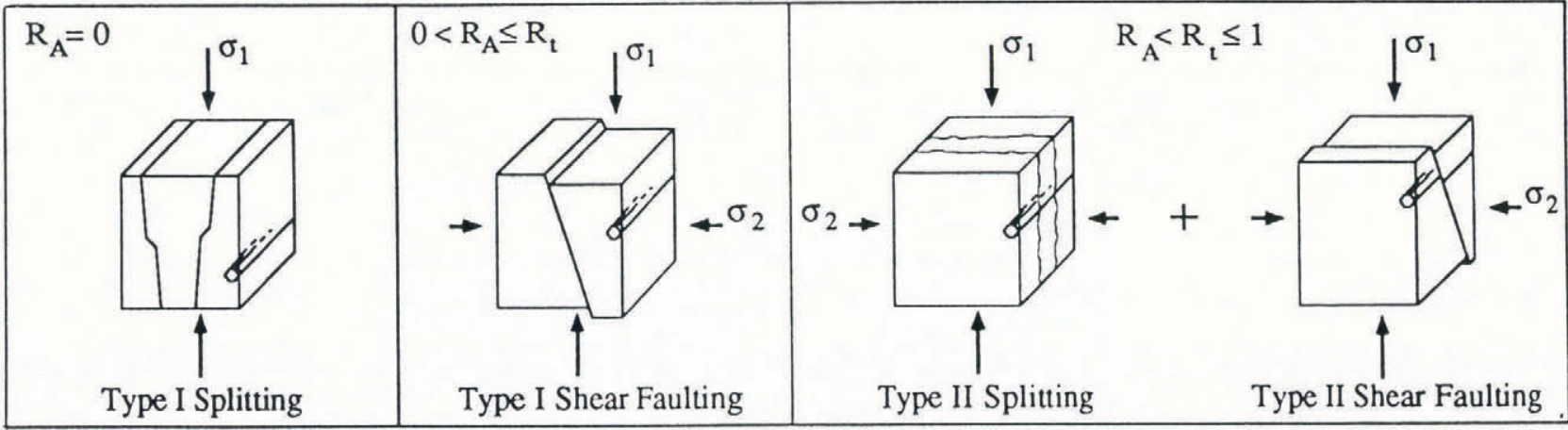

Fig. 5. Schematic sketch of failure modes for type-A confinement of salt-water ice loaded normal to the columns. 


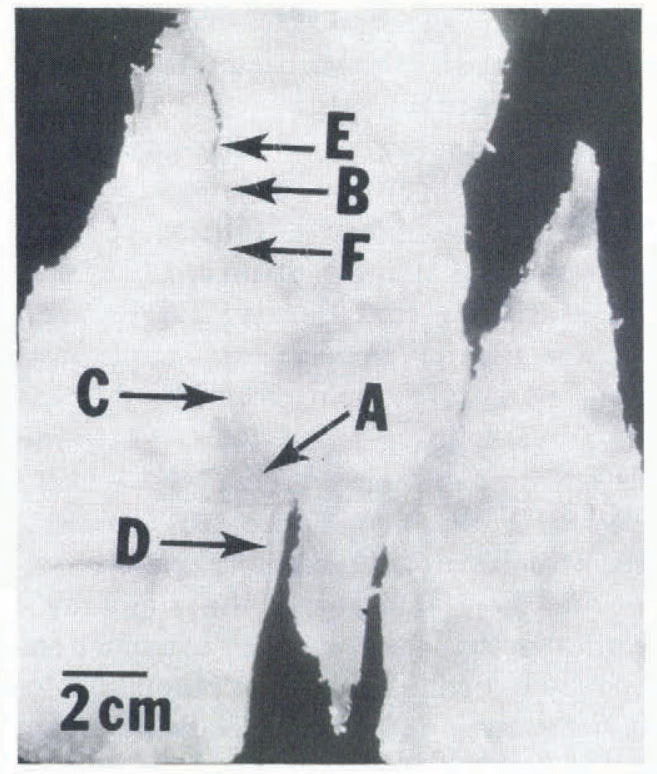

Fig. 6. Typical type $I$ splitting failure $\left(R_{\mathrm{A}}=0, T=\right.$ $-10^{\circ} \mathrm{C}$ ) for salt-water ice loaded normal to the columns, seen under cross-polarized light. The stress axis $\left(\sigma_{1}\right)$ is vertical and the column orientations are orthogonal to the page. Note the inclined cracks at $A$ and $B$, with axial extensions at $C$ and $D$, and $E$ and $F$.

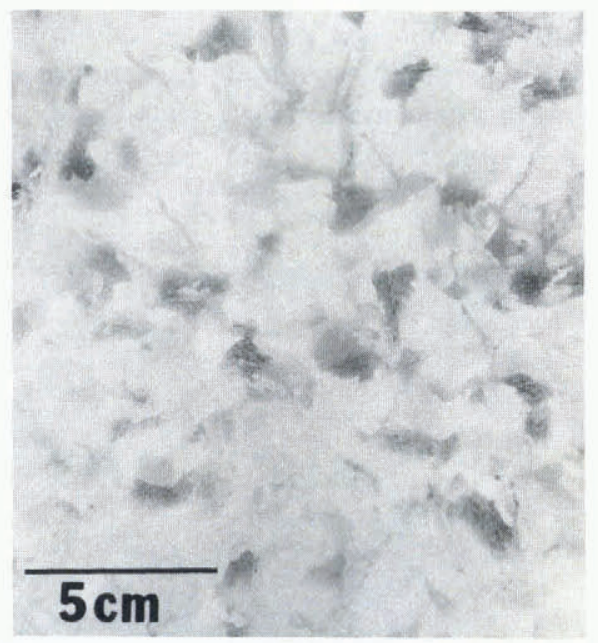

(a) splits. This resulted in the break-up of the sample into a number of smaller almost undamaged pieces or shards, and was termed type I splitting. Figure 6 shows an example of this mode.

Upon the application of the confining stress (i.e. $0<$ $R_{\mathrm{A}} \leq R_{\mathrm{t}}$ ), the samples did not break up into shards. Instead, they failed by the formation of a macroscopic shear fault in the loading plane. This fault was a relatively distinct line demarking regions of opposed sliding and was inclined about $30^{\circ}$ to the axis of higher load. This mode, termed type I faulting, showed considerable cracking and fragmentation concentrated about one grain diameter from the fault. Experiments performed on "microsimilar" plates showed essentially identical failures in this mode, down to the level of the specific grains which fractured (Fig. 7), indicating that failure was specifically related to the microstructure and not to either the specimen shape or the boundary conditions.

Although the terminology "shear-faulting" used here is consistent with the rock-mechanics usage, this does not necessarily imply that these features originated solely from a microscopic shear process. This terminology essentially arises from the observation that, once formed, continued deformation can cause the opposing sides of the fault to slide.

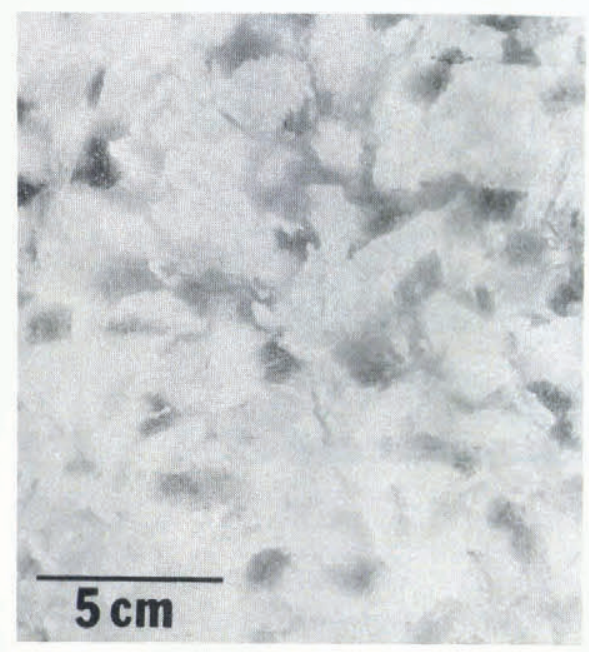

(b)

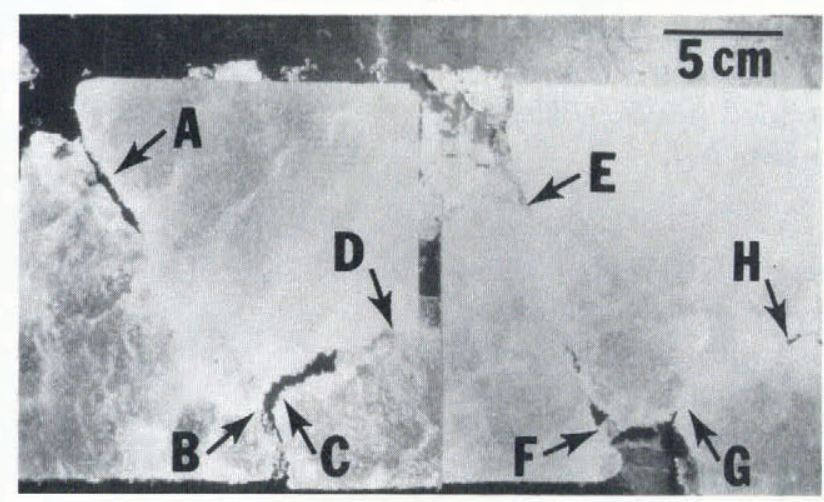

(c)

Fig. 7. Typical type I faulting failure of two micro-similar plates of salt-water ice $\left(R_{\mathrm{A}}=0.15, T=-10^{\circ} C\right)$. The major stress axis $\left(\sigma_{1}\right)$ is vertical, the minor stress axis $\left(\sigma_{2}\right)$ is horizontal and the column orientations are orthogonal to the page; $(a)$ and $(b)$ are undeformed microstructures seen under cross-polarized light, (c) shows type I faults in specimens (a) and (b), respectively. Note the similarity of the microstructures in the two specimens and location of the faults at $A-B$ and $C-D$ compared to $E-F$ and $G-H$. 


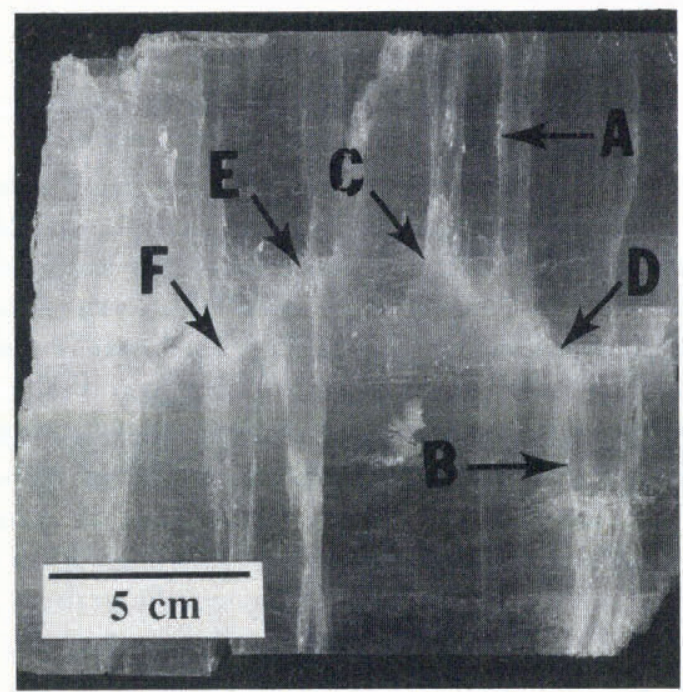

(a)

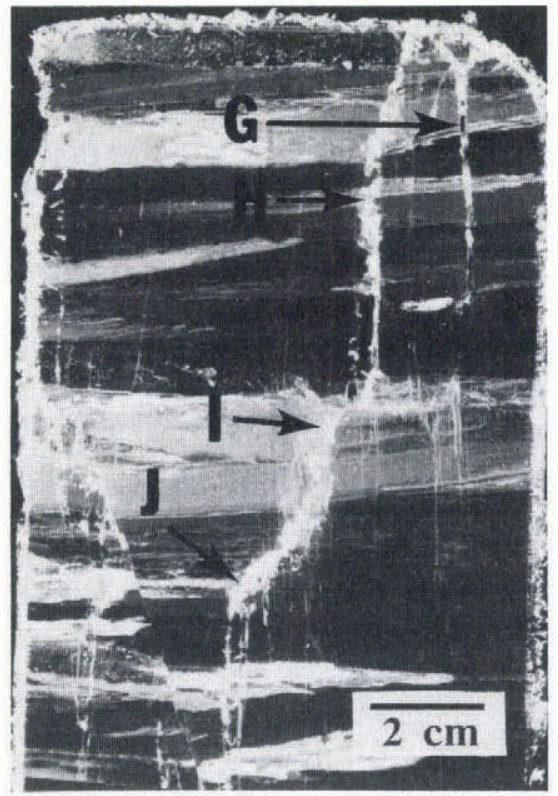

(b)

Fig. 8. Typical combination failure of salt-water ice $\left(R_{\mathrm{A}}=0.2, T=-10^{\circ} \mathrm{C}\right)$. The major stress axis $\left(\sigma_{1}\right)$ is vertical, the minor stress axis $\left(\sigma_{2}\right)$ is orthogonal to the page and the column orientations are horizontal; (a) failed sample showing both type II splitting at $A$ and $B$, and type II faulting along $C-D$ and $E-F$; (b) thin section under cross-polarized illumination showing both type II splitting at $G$ and $H$, and type II faulting along $I-\mathcal{J}$.

For the higher-confinement regime $\left(R_{\mathrm{A}}>R_{\mathrm{t}}\right)$, failure occurred out of the loading plane through a combination of splitting and shear faulting. An example is shown in Figure 8. Here, the splitting was again parallel to the axis of higher load, but the splits cut through the columnar grains parallel to the plate face; the faulting was out of the plane of loading. These types were termed type II splitting and type II faulting to distinguish them from the other types.

These failure modes were essentially the same as those found for fresh-water columnar ice by Smith and Schulson (1993) under similar test conditions. This point, when combined with the similarity in the failure envelopes, further suggests that the brittle biaxialcompressive failure of the two materials is governed by similar physical processes.

It is interesting to note that similar changes in failure mode with confinement are also seen in rock. For example, in the compressive failure of granite, a transition from axial splitting to inclined shear faulting occurs upon triaxial confinement (Jaeger and Cook, 1969). Under biaxial compression, sandstone plates (Maso and Lerau, 1980) split parallel to the plate face, like the type II splitting found here. These rocks are essentially isotropic and have a grain-size which is very small relative to the sample size, in contrast to the anisotropic structure of the coarsely grained ice tested here. Despite these differences, the similarity of the failures indicates that these changes in failure mode are more generally indicative of brittle-compressive behavior under confining stress rather than ice being unique in its response. The ice studied here, however, does display two distinct regimes of behavior which are, in part, attributable to its anisotropic structure and these are discussed more extensively below.

\subsection{Damage}

Owing to the opacity of saline ice, little macroscopic damage was visible to the unaided eye until close to the failure stress. Some grain-boundary cracks inclined to $\sigma_{1}$ were observed by eye and some macroscopic evidence of wing-crack formation was seen under low confinement (i.e. within regime 1). To assess damage in detail, two

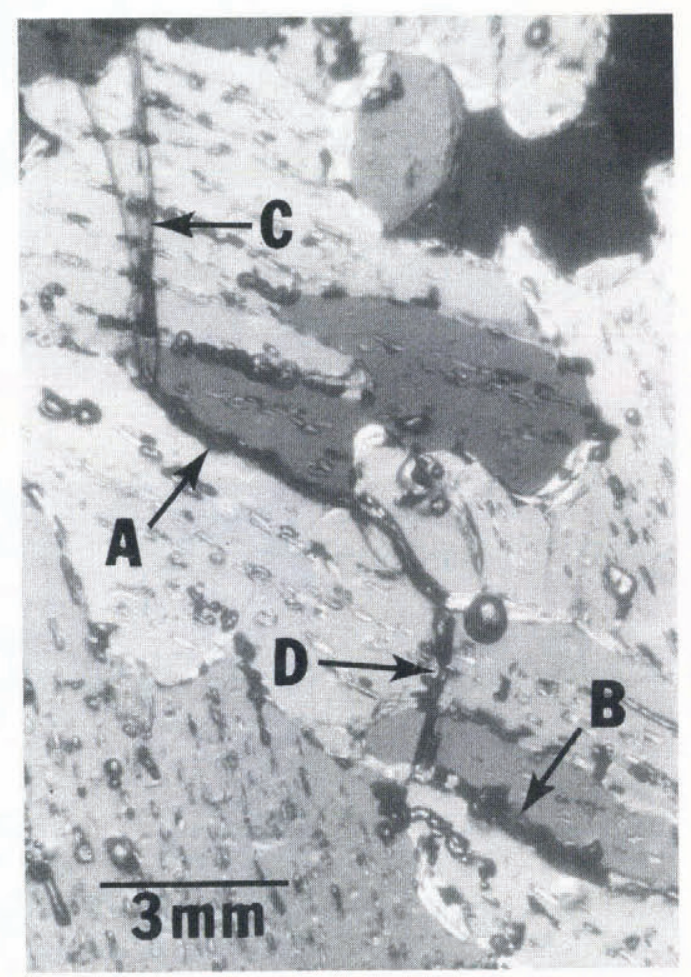

Fig. 9. Inclined grain-boundary cracks with wing cracks in salt-water ice $\left(R_{\mathrm{A}}=0, T=-10^{\circ} \mathrm{C}\right)$, shown under crosspolarized light. The stress axis $\left(\sigma_{1}\right)$ is vertical and the column orientations are orthogonal to the page. Note the grain-boundary cracks at $A$ and $B$, and wing cracks at $C$ and $D$. 
series of micro-similar plates were tested by single-pulse loading at $-10^{\circ} \mathrm{C}$ followed by thin-sectioning after the load pulse. Experiments at $R_{\mathrm{A}}=0$ and $R_{\mathrm{A}}=0.15$ were performed; one set of plates was used for each ratio. The first plate in each series was loaded monotonically to failure to determine the approximate failure stress for
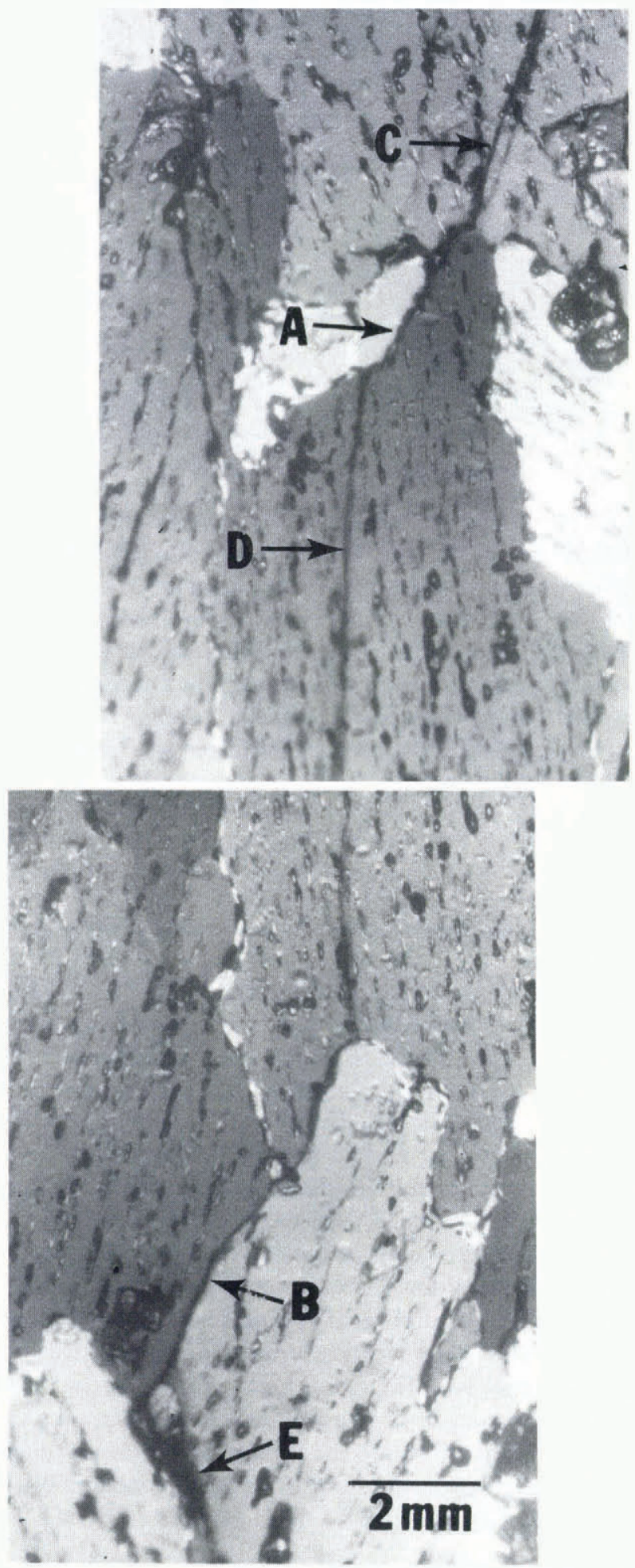

Fig. 10. Wing cracks linking to form a macroscopic axial crack in salt-water ice $\left(R_{\mathrm{A}}=0, T=-10^{\circ} \mathrm{C}\right)$, shown under cross-polarized light. The stress axis $\left(\sigma_{1}\right)$ is vertical and the column orientations are orthogonal to the page. Note the grain-boundary cracks at $A$ and $B$, and wing cracks at $C, D$ and $E$. others in the series. Other plates were pulse-loaded to stress levels less than the failure stress.

\subsubsection{Wing cracks}

Grain-boundary cracks with angled extensions, so-called "wing cracks", were found following uniaxial pulseloading. These wing cracks, shown in Figures 9 and 10, tended to align with the axis of load. As found for freshwater ice, the parent crack which sprouted wings was located at a grain boundary, inclined to the stress axis. In the saline ice, however, the parent inclined cracks were often found to be shorter than the grain-boundary facet, running between brine pockets on the boundary. In both types of ice, the wings generally propagated through the grains and not along the grain boundaries.

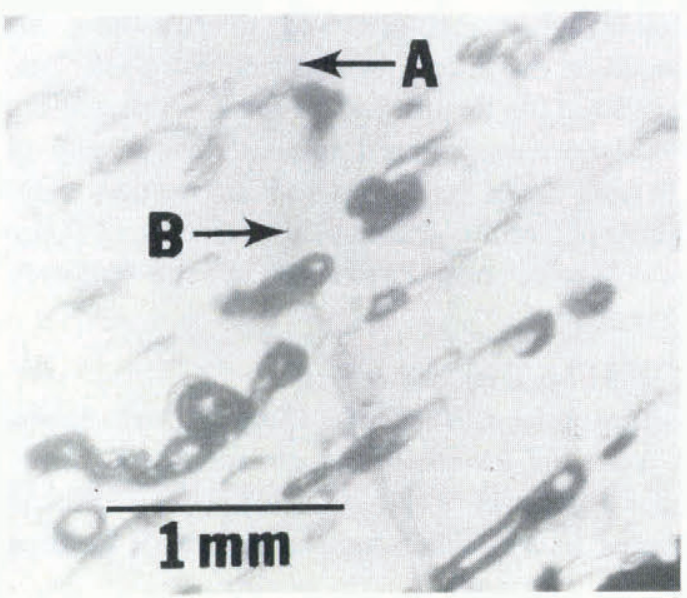

(a)

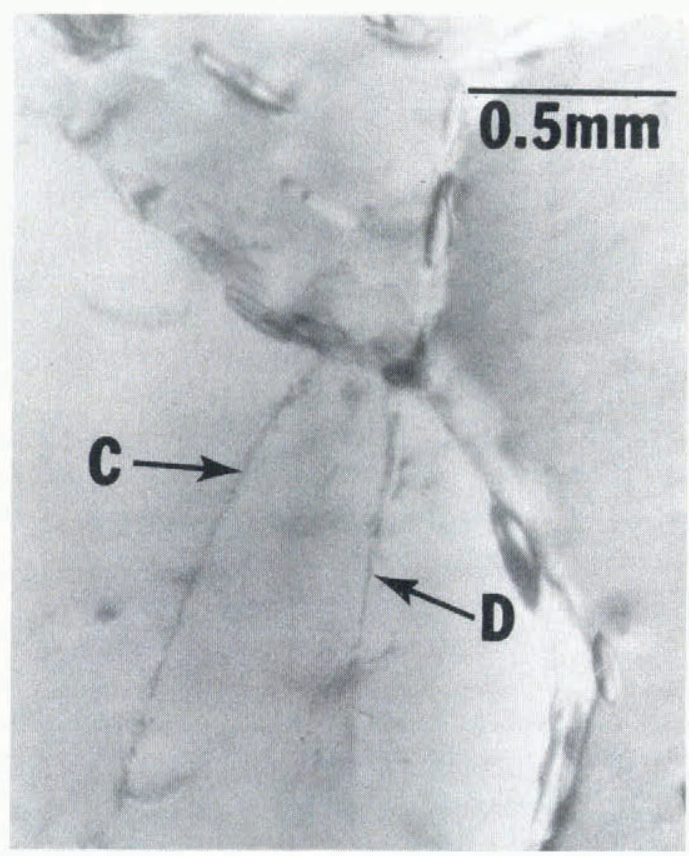

(b)

Fig. 11. Cracks from brine pockets in salt-water ice $\left(R_{\mathrm{A}}=0.15, T=-10^{\circ} \mathrm{C}\right)$, shown under cross-polarized light. The major stress axis $\left(\sigma_{1}\right)$ is vertical, the minor stress axis $\left(\sigma_{2}\right)$ is horizontal and the column orientations are orthogonal to the page; (a) cracks within a grain at $A$ and $B ;(b)$ cracks at $C$ and $D$ near a triple point. 


\subsubsection{Cracks at brine pockets}

In addition to grain-boundary and wing cracks, some cracks appeared to originate from the brine pockets within a grain (Fig. 11a). They, too, tended to align with the stress axis. They were not present in undeformed ice. These cracks were likely related to a localized stress concentration caused by the pockets. Another scenario was observed (Fig. 11b) where brine-pocket cracks were found in the vicinity of a triple-point junction. Crack nucleation in columnar ice at triple points has been shown to occur along the grain-boundary facets from a junction in ice (Frost and Smith, 1992) and was attributed to elastic mismatch betwen the grains.

\subsubsection{Type I splitting, wing cracks and collapse}

From the thin-section analysis, wing extensions from inclined cracks were observed to run long distances compared to the length of the inclined part. The wings appeared to link, forming axial splits, as shown in Figure 10. Final failure appeared to result from axial splitting due to wing-crack extension and interaction, assisted by fragmentation of the grains. All the details of this process, however, were not captured in the pulse-loading experiments.

\subsubsection{Type I faulting and collapse}

In regime $1\left(0<R_{\mathrm{A}} \leq R_{\mathrm{t}}\right)$, final failure appeared to result from the formation of a macroscopic shear fault, angled approximately $30^{\circ}$ to the axis of higher load, as mentioned above. There was considerable local cracking

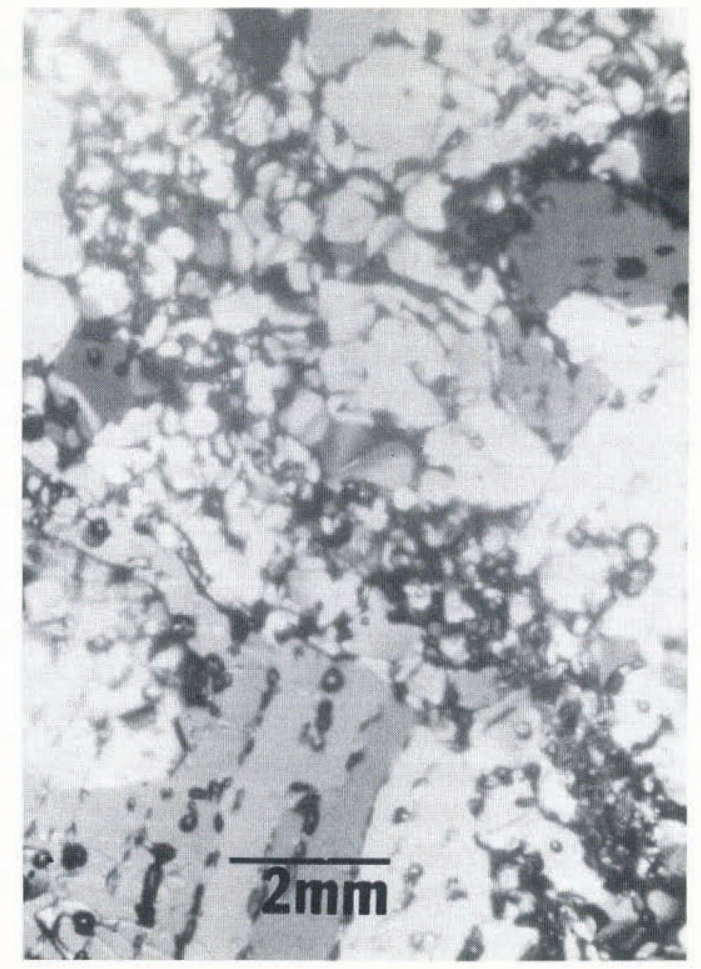

Fig. 12. Fragmented ice forming a zone in a salt-water specimen $\left(R_{\mathrm{A}}=0.2, T=-10^{\circ} \mathrm{C}\right)$, shown under crosspolarized light. The major stress axis $\left(\sigma_{1}\right)$ is vertical, the minor stress axis $\left(\sigma_{2}\right)$ is horizontal and the column orientations are orthogonal to the page. The fragmented ice leads to local regions of instability which are important in the overall failure process.

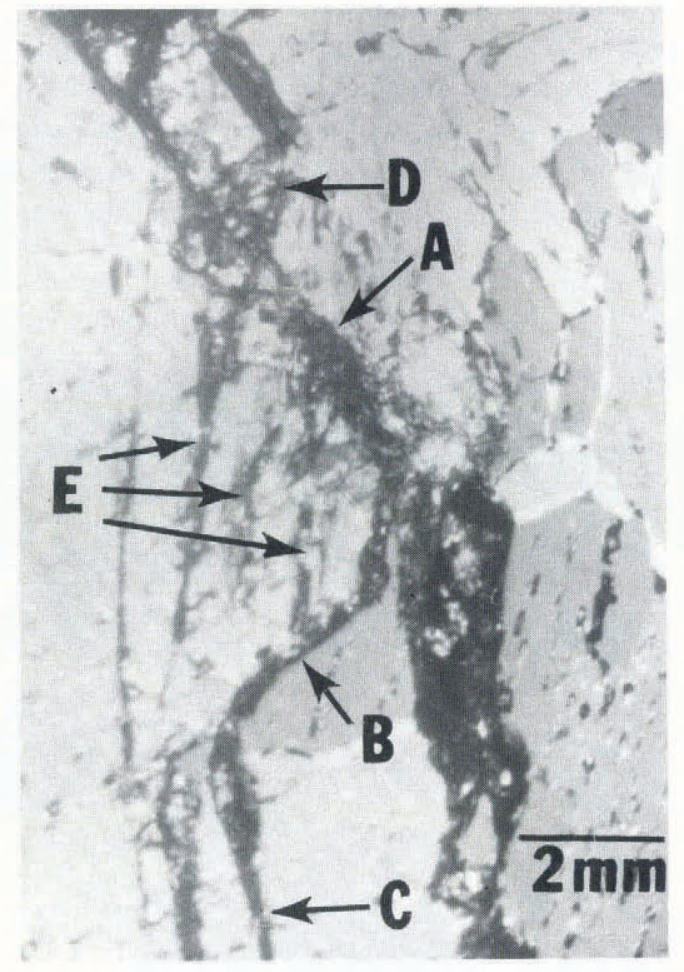

Fig. 13. Feather fractures in a salt-water ice $\left(R_{\mathrm{A}}=\right.$ $\left.0.15, T=-10^{\circ} \mathrm{C}\right)$, shown under cross-polarized light. The major stress axis $\left(\sigma_{1}\right)$ is vertical, the minor stress axis $\left(\sigma_{2}\right)$ is horizontal and the column orientations are orthogonal to the page. Note the larger inclined grainboundary cracks at $A$ and $B$ and wing-crack extensions along the axis of higher load at $C$ and $D$; feather fractures at $E$. The feather fractures are explained by Hertzian fracture at non-conformal points of contact of the parent crack faces.

within 1-2 grain diameters of the fault, revealed by thin sections (Fig. 12). The grains adjacent to the fault contained multiple axial cracks inclined $15-45^{\circ}$ to the major loading axis, extending from grain-boundary cracks (Fig. 13). These features were very similar in appearance to those seen in local shear-fault zones in fresh-water columnar ice (Smith and Schulson, 1993) under biaxial loading and in granite (Wong, 1982) and sandstone (Conrad and Friedman, 1976) under triaxial deformation. These cracks were called "feather fractures" by Conrad and Friedman, a terminology also used here.

The "fragmentation" seen in the ice was a breakdown of the original grain structure into smaller fragments. This fragmentation appears to be assisted by the brine pockets. The "feather" cracks appear to intersect preferentially the brine pockets which results in a local region of small particles of ice of a size approximately equal to the inter-pocket spacing, 0.1 $0.5 \mathrm{~mm}$ (Figs 12, 13 and 14).

\subsubsection{Combined failure modes and collapse}

The failure seen for $R_{\mathrm{A}}>R_{\mathrm{t}}$ occurred through a combination of type II splitting and type II faulting, as noted above. The important failure processes occurred out of the plane of the smaller grain dimension (i.e. the ice failed out of the loading plane). No detailed assessment of damage was made for this regime. 


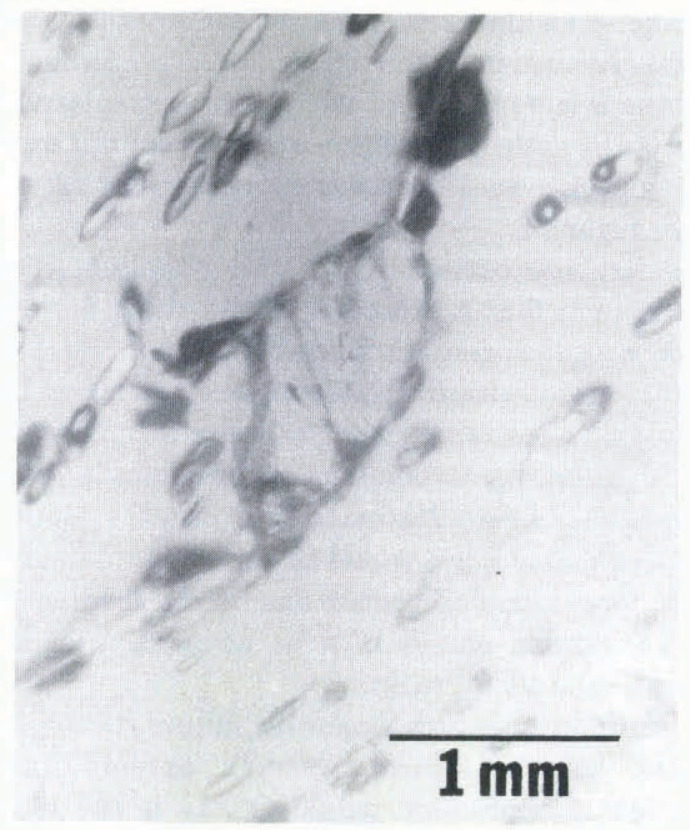

Fig. 14. Cracks connecting brine pockets in a salt-water ice $\left(R_{\mathrm{A}}=0, T=-10^{\circ} \mathrm{C}\right)$, shown under cross-polarized light. The major stress axis $\left(\sigma_{1}\right)$ is vertical, the minor stress axis $\left(\sigma_{2}\right)$ is horizontal and the column orientations are orthogonal to the page. This illustrates the role of brine pockets in brittle-regime damage of salt-water ice.

\section{DISCUSSION}

The observations reported here closely resemble those reported for fresh-water ice. The explanations of the behavior are essentially the same as those first presented by Schulson and Smith (1992) and discussed further by Smith and Schulson (1993).

The increase in $\sigma_{\text {If }}$ with $R_{\mathrm{A}}$ under low confinement (regime 1) and the damage detected in this regime indicate that frictional crack sliding is important. This is part of the wing-crack mechanism (e.g. Griffith, 1924; McClintock and Walsh, 1963; Nemat-Nasser and Horii, 1982; Ashby and Hallam, 1986) that was invoked by Smith and Schulson (1993) to account for the variation in failure stress with confinement under biaxial loading for fresh-water columnar ice. The rise in $\sigma_{\text {If }}$ with $R_{\mathrm{A}}$ can be explained within the context of the model by assuming that the compressive constraint opposes crack sliding by both reducing the shear stress at the crack faces and by increasing the normal stress (and hence the sliding friction) across the crack. This means that higher confinement produces greater suppression and so a higher failure stress would result on that basis only.

An important issue in the application of the model is whether cracks are closed under the compressive stress. Grain-boundary cracks in fresh-water granular and columnar ice are observed to be uneven in texture (Schulson and others, 1989; Smith, 1991; Smith and Schulson, 1993), somewhat like a "cornflake". While they are certainly open when formed (hence, observable to the naked eye), with an infinitesimal displacement in-plane, the non-conformal crack surfaces can come back into contact at discrete points. Thus, a quasi-closed (but observable) crack can result. Although the observation of grain-boundary cracks by eye in saline ice is difficult, there is no reason to expect that the crack surfaces are very different than from those seen in fresh-water ice. On this basis, we choose the frictional crack-sliding approach for our subsequent analysis. This argument for crack closure and for the importance of friction is rather different from the mathematical treatment of crack closure under compression, where the crack is assumed to be a flat ellipsoid. Digby and Murrell (1976) found that the stress to close such a cavity is approximately 10 times the tensile strength of the material. In the present study, the failure stresses at high confinement are roughly sufficient to close the cracks by this calculation $\left(10 \sigma_{\mathrm{T}} \approx 10 \mathrm{MPa}\right.$ for ice) but open cracks could not explain the formation of feather fractures from parent, grain-boundary cracks observed in experiments. Smith and Schulson (1993) observed the formation of feather fractures in biaxial compression at $\approx 0.9$ of the failure stress (5.9 $\mathrm{MPa} / 6.3 \mathrm{MPa}$; i.e. $<10 \mathrm{MPa}$ ) from grainboundary cracks in fresh-water ice, captured on highspeed film. Post-mortem thin sections in the present work confirm the formation of feather fractures in saline ice (Fig. 13) and it is reasonable to expect that they formed in the same way.

The physical evidence validates applying the concept of inclined crack sliding to salt-water ice. Figure 6 shows shards of saline ice after failure under uniaxial loading. Inclined steps are present at the shard edges (shown at A and B) and have straight segments adjacent to them, consistent with wing-crack extensions at either end of the inclined part (shown at C, D, E and F). Figures 9 and 10 show inclined grain-boundary cracks with short wing cracks at either end, from the pulse-loading tests under uniaxial loading. These wing cracks are located as required by inclined crack sliding. Similar features have been found in fresh-water columnar ice under uniaxial stress by Schulson and others (1991b) and Cannon and others (1990), and under biaxial stresses by Smith and Schulson (1993).

Schulson and others (1991a) formulated the frictional crack-sliding model to give the $\sigma_{\mathrm{lf}}-R_{\mathrm{A}}$ relationship as:

$$
\sigma_{\text {If }}=\sigma_{\mathrm{U}}(1-\mu) /\left\{\left(1-R_{\mathrm{A}}\right)(1-\mu)-2 R_{\mathrm{A}} \mu\right\}
$$

where $\sigma_{\mathrm{U}}$ is the uniaxial brittle-failure stress in compression and $\mu$ is the ice/ice kinetic friction coefficient. Upon equating Equations (3) and (1) and using $\sigma_{2}=R_{\mathrm{A}} \sigma_{1}$, it follows that:

$$
k_{1}=(1+\mu) /(1-\mu) .
$$

At $-10^{\circ} \mathrm{C}, \mu \approx 0.5$ (Jones and others, 1991) and so Equation (4) gives $k_{1}=3$, in agreement with the value in Table 2. Likewise, $\mu=0.8$ for $-40^{\circ} \mathrm{C}$ from Jones' data which predicts that $k_{1}=7$. This value does not compare as favorably with Table 2 but the difference may be due to the more limited data.

It seems reasonable, then, that inclined crack sliding can be invoked to explain the origin of axial splits in saline ice. However, as for fresh-water ice, propagation of axial splits is insufficient to produce final collapse of the ice. To account for this, Smith and Schulson (1993) suggested that localized fragmentation of the ice is 
another key element in the brittle behavior. Essentially, if a small volume of the ice breaks into fragments in the vicinity of the axial cracking, then local regions of instability can develop. These regions, linked with the axial splits, will cause overall instability and lead to collapse.

An explanation of the origin of fragmented ice appears to be related to the feather fractures observed proximate to inclined cracks, discussed above. Smith and Schulson (1993) suggested that feather fractures in ice are formed due to Hertzian contact of asperities on the rough, opposing faces of the parent, inclined crack under the component of the applied stress normal to the parent crack. These points of contact lead to local tensile fracture (Lawn and Wilshaw, 1975) and thus would account for the observations. The observations also suggest that interaction between feather fractures and the sub-grain brine pockets may also be important, as this assists in the fragmentation process (Figs 13 and 14). An alternative explanation has been given by Fonseka and others (1985). They described a process in which fragmentation of rock can occur due to crack interactions between overlapping cracks that are inclined to the major principal stress. It is entirely possible that both of these processes occur in ice.

We now shift our attention to the second regime of behavior (i.e. $R_{\mathrm{A}}>R_{\mathrm{t}}$ ), where the failure mode was out of the loading plane. One approach to explain this regime is that failure is attributable to a critical tensile strain, $\epsilon_{3}{ }^{*}$, being reached in the direction of no load. Assuming isotropy in the loading plane, this strain is given by $\epsilon_{3}{ }^{*}=$ $-\nu / E\left(\sigma_{1 \mathrm{f}}+\sigma_{2 \mathrm{f}}\right)$, where $\nu$ is Poisson's ratio and $E$ is Young's modulus; $\sigma_{1 \mathrm{f}}$ and $\sigma_{2 \mathrm{f}}$ are the major stress and confining stress at failure, respectively. This equation can be re-arranged to give:

$$
\sigma_{1 \mathrm{f}}+\sigma_{2 \mathrm{f}}=-\epsilon_{3}{ }^{*} E / \nu
$$

where $-\epsilon_{3}{ }^{*} E / \nu$ is equivalent to $k_{2}$ of Equation (2). Evaluating Equation (5) for data obtained at $-10^{\circ} \mathrm{C}$, $k_{2}=16 \mathrm{MPa}$ (Table 2), $\nu \approx 0.3$ (Schwartz and Weeks, 1977) and $E=7 \mathrm{GPa}$ (Schwartz and Weeks, 1977), the critical tensile strain $\epsilon_{3}{ }^{*}$ is $\approx 0.0007$. This value is about 6 times the tensile failure strain measured along the columnar axes (at $\dot{\epsilon}=10^{-3} \mathrm{~s}^{-1}$ at $-10^{\circ} \mathrm{C}$ ) reported by Kuehn and others (1990), indicating rather poor quantitative agreement. Nevertheless, following this approach further, the transition between regime 1 and regime 2 would be related to the inability of the anisotropy of the ice samples to keep the deformation in the plane of the applied loads at higher values of $\sigma_{2}$. In fact, if the ice were isotropic, regime 1 would probably not be distinct from regime 2. While this approach could account qualitatively for the behavior, the absence of quantitative agreement, plus the fact that it provides no insight as to how cracks parallel to the loading plane can form, suggests that some other mechanism underlies the failure of the ice under the higher confining stress.

Another approach is that the formation of new secondary tensile cracks from parent cracks may dominate the behavior. The parent cracks form first with crack normals oriented in the plane of loading (owing to the anisotropy of the columnar grains); the secondary cracks can form in any orientation but, when $\sigma_{2}$ is small $\left(R_{\mathrm{A}}<R_{\mathrm{t}}\right)$, form with their faces oriented in the plane of loading also owing to the anisotropy of the material. At higher confinement, however, formation in this plane is suppressed, in which case secondary cracks form parallel to the stress-free surface. From this scenario, we can develop an alternative expression for the failure stress in regime 2.

The key assumption (Smith and Schulson, 1993) in the analysis is that a Hertzian tensile stress develops at discrete points of contact across the rough crack faces. This stress scales with the compressive stress normal to the crack plane. Nucleation of one or more secondary tensile cracks then occurs at points of highest tensile stress. As already noted, the nucleation of these cracks under higher levels of confining stress would be expected to occur along planes whose normals project out of the loading plane. Type II splitting would then be accounted for by the propagation of such cracks.

To develop an expression for the failure stress based on Hertzian contact failure, we will assume that the nucleation of secondary tensile cracks is the strengthlimiting process. Hertzian contact results in a local tensile stress of the form $\sigma_{\text {tensile }}=f\left(\sigma_{\mathrm{N}}\right)$, where $\sigma_{\mathrm{N}}$ is the stress normal to the crack plane. If we ignore the contribution to the tensile stress due to traction at the crack surfaces, then the maximum tensile stress is about $\{(1-2 \nu) / 3\} \sigma_{N}$, where $\nu$ is the Poisson's ratio (Johnson, 1985). Assuming an initial parent crack inclined at $45^{\circ}$ to the major stress with crack forces orthogonal to the loading plane (in reasonable accord with observation), then $\sigma_{\mathrm{N}} \approx$ $\left(\sigma_{1}+\sigma_{2}\right) / 2$. Combining these expressions and setting the local tensile stress to the tensile strength of the ice $\left(\sigma_{\text {tensile }}=\sigma_{\mathrm{T}}\right)$ for nucleation of a secondary crack, we get a criterion for the failure stress in the higher confinement regime:

$$
\sigma_{1}+\sigma_{2}=6 \sigma_{\mathrm{T}} /(1-2 \nu) \text {. }
$$

The righthand side of Equation (6) is equivalent to $k_{2}$ of Equation (2). Evaluating Equation (6) with appropriate values, $\sigma_{\mathrm{T}}=1 \mathrm{MPa}$ for $-10^{\circ} \mathrm{C}$ (Dykins, 1966) and $\nu \approx$ 0.3 , we get the expression $\sigma_{1}=14-\sigma_{2}$, which is in fair agreement with the data (Table 2). We would expect a small temperature sensitivity of this expression, in accord with the variation of the tensile strength and Poisson's ratio; however, data at $-40^{\circ} \mathrm{C}$ for these parameters are not available in the literature.

Concerning the assumption that the cracks in the ice were inclined at about $45^{\circ}$ to the major stress axis, there is some evidence to support this, but a statistical study was not performed. If, instead, a random distribution of crack orientations was present, then the normal stress at the crack would be maximum for cracks $90^{\circ}$ to $\sigma_{1}$, implying that the failure stress at higher confinement (i.e. $R_{\mathrm{A}}>R_{\mathrm{t}}$ ) would be independent of $\sigma_{2}$. Some of the scatter in the data may be attributable to a distribution in crack orientation with respect to $\sigma_{1}$.

We recognize that this analysis is far from complete and that more direct evidence of Hertzian-type contact fracture is needed to support the model of regime 2. Yet the analysis appears to explain quantitatively the failure of the ice and seems to capture the physical processes. However, more detailed observations are needed to verify the interpretation. 


\section{CONGLUSIONS}

Biaxial compression experiments on saline columnar ice loaded normal to the columns under across-column confinement (i.e. the confining stress is applied orthogonal to the long axis of the columnar grains; type-A confinement) have been performed at $\dot{\epsilon} \approx 10^{-2} \mathrm{~s}^{-1}$ at $-10^{\circ}$ and $-40^{\circ} \mathrm{C}$. Under these conditions the ice is brittle. It can be concluded that:

1. (a) The brittle-failure stress first rises sharply with confinement $\left(R_{\mathrm{A}}=\sigma_{2} / \sigma_{1}\right)$ and then tends to decrease as $\sigma_{2}$ increases further.

(b) A transition in behavior occurs at $R_{\mathrm{A}}=R_{\mathrm{t}} \approx 0.2$ at $-10^{\circ} \mathrm{C}$ and at $\approx 0.1$ at $-40^{\circ} \mathrm{C}$.

(c) The failure mode changes from either axial splitting $(R=0)$ or shear faulting in the loading plane $\left(0<R_{\mathrm{A}} \leq R_{\mathrm{t}}\right)$ to a combined mode of splitting across the columns and shear faulting out of the loading plane $\left(R_{\mathrm{A}}>R_{\mathrm{t}}\right)$.

2. The brittle-failure envelope resembles a truncated Coulomb envelope.

3. Localized fragmentation of the ice is important in the brittle-failure process.

4. The first regime of confinement-dependent behavior $\left(0<R_{\mathrm{A}}<R_{\mathrm{t}}\right)$ can be explained in terms of the frictional crack-sliding mechanism.

5. The second regime of confinement-dependent behavior $\left(R_{\mathrm{t}}<R_{\mathrm{A}}<1\right)$ can be explained in the context of contact fracture at closed crack faces.

6. The brittle compressive behavior of salt-water columnar ice is essentially the same as the behavior of freshwater columnar ice.

\section{ACKNOWLEDGEMENTS}

The authors would like to thank Professor H. Frost and Dr J. Zhang for valuable discussions; G. Kuehn, D. Jones and D. Fifolt for technical assistance; and M. Linton for help with the microstructural measurements. The authors would also like to thank the anonymous reviewer for several helpful suggestions to improve the original manuscript. This work was funded by the U.S. Office of Naval Research through a University Research Initiative grant No. N00014-86-K-0695 and through grant No. N00014-92-J-1279. This study was performed at the Ice Research Laboratory of the Thayer School of Engineering, which is operated through additional funding provided by the U.S. Army Research Office, the U.S. Coast Guard, the Minerals Management Service, by Conoco, Exxon, Mobil and MTS Corporation.

\section{REFERENCES}

Ashby, M.F. and S.D. Hallam. 1986. The failure of brittle solids containing small cracks under compressive stress states. Acta Metallurgica et Materialia, 34(3), 497-510.

Cannon, N. P., E. M. Schulson, T. R. Smith and H.J. Frost. 1990. Wing cracks and brittle compressive fracture of ice. Acta Metallurgica et Materialia, 38(10), 1955-1962.
Conrad, R. E., II and M. Friedman, 1976. Microscopic feather fractures in the faulting process. Tectonophysics, 33, 187-198.

Cox, G.F.N. and W.F. Weeks. 1982. Equations for determining the gas and brine volumes in sea ice samples. CRREL Rep. 82-30.

Cox, G.F.N., J.A. Richter-Menge, M. Mellor, W.F. Weeks and H. W. Bosworth. 1984. Mechanical properties of multi-year sea ice. Phase I: Test results. CRREL Rep. 84-9.

Cox, G.F.N. and 6 others. 1985. Mechanical properties of multi-year sea ice. Phase II: Test results. CRREL Rep. 85-16.

Digby, P.J. and S.A.F. Murrell. 1976. The deformation of flat ellipsoidal cavities under large confining pressures. Bull. Seismol. Soc. Am., 66(2), 425-431.

Dykins, J.E. 1966. Tensile properties of sea ice grown in a confined system. In Oura, H., ed. Physics of snow and ice. International Conference on Low Temperature Science ..., 1966, Sapporo, Japan. Proceedings. Vol. 1. Sapporo, Hokkaido University. Institute of Low Temperature Science, $523-537$.

Fonseka, G. M., S. A. F. Murrell and P. Barnes. 1985. Scanning electron microscope and acoustic emission studies of crack development in rocks. Int. J. Rock Mech. Min. Sci. Geomech. Abstr., 22(5), 273-289.

Frederking, R. 1977. Plane-strain compressive strength of columnargrained and granular-snow ice. J. Glaciol., 18(80), 505-516.

Frost, H.J. and T. R. Smith. 1992. Crack nucleation in columnar ice. In IAHR 1992. 11th International Symposium on Ice, Banff, Alberta, Canada, June 15-19, 1992. Proceedings. Vol. 2, 1075-1086.

Gow, A.J., W.B. Tucker and W.F. Weeks. 1987. Physical properties of summer sea ice in the Fram Strait, June-July 1984. CRREL Rep. 87-16.

Griffith, A.A. 1924. Theory of rupture. In Proceedings of the First International Congress on Applied Mechanics, Delft, Holland, 55-63.

Häusler, F.U. 1981. Multiaxial compressive strength tests on saline ice with brush-type loading platens. In IAHR International Symposium on Ice, Québec, Canada, July 27-31, 1981. Proceedings. Vol. II. Québec, Université Laval, 526-536.

Hăusler, F. U. 1983. Comparison between different yield functions for saline ice. Ann. Glaciol., 4, 105-109.

Jaeger, J. C. and N. G. W. Cook. 1969. Fundamentals of rock mechanics. London, Methuen.

Johnson, K. L. 1985. Contact mechanics. Cambridge, Cambridge University Press.

Jones, D. E., F.E. Kennedy and E. M. Schulson. 1991. The kinetic friction of saline ice against itself at low sliding velocities. Ann. Glaciol., 15, 242-246.

Kuehn, G. A., R. W. Lee, W. A. Nixon and E. M. Schulson. 1990. The structure and tensile strength of first-year sea ice and laboratorygrown saline ice. 7. Offshore Mech. Arct. Eng., 112, 357-363.

Langway, C. C. , Jr. 1958. Ice fabrics and the universal stage. SIPRE Tech. Rep. 62.

Lawn, B. and R. Wilshaw, 1975. Review of indentation fracture: principles and applications. J. Mater. Sci., 10, 1049-1081.

McClintock, F.A. and J. B. Walsh. 1963. Friction on Griffith's cracks in rocks under pressure. In Proceedings. 4th U.S. National Congress on Applied Mechanics. Vol. 2. New York, American Society of Mechanical Engineers, 1015-1020.

Maso, J.-C. and J. Lerau. 1980. Mechanical behavior of Darney sandstone (Vosges, France) in biaxial compression. Int. J. Rock Mech. Min. Sci. Geomech. Abstr., 17, 109-115.

Murrell, S.A.F., P. R. Sammonds and M. A. Rist. 1991. Strength and failure modes of pure ice and multi-year sea ice under triaxial loading. In Jones, S.J., R.F. McKenna, J. Tillotson and I.J. Jordaan, eds. Ice-Structure Interaction. IUTAM/IAHR Symposium, St. John's, Newfoundland, Canada, 1989. Berlin, Springer-Verlag, 339-361.

Nemat-Nasser, S. and H. Horii. 1982. Compression-induced nonplanar crack extension with application to splitting, exfoliation, and rockburst. J. Geophys. Res., 87(B8), 6805-6821.

Richter-Menge, J.A., G.F.N. Cox, N. Perron, G. Durell and H. W. Bosworth. 1986. Triaxial testing of first-year sea ice. CRREL Rep. 86-16.

Sammonds, P.R., S. A. F. Murrell and M. A. Rist. 1989. Fracture of multi-year sea ice under triaxial stresses: apparatus description and preliminary results. J. Offshore Mech. Arct. Eng., 111, 258-263.

Schulson, E.M. and T.R. Smith. 1992. The brittle compressive failure of columnar ice under biaxial loading. In IAHR 1992. 11th International Symposium on Ice, Banff, Alberta, Canada, June 15-19, 1992. Proceedings. Vol. 2, 1047-1064.

Schulson, E. M., S. G. Hoxie and W.A. Nixon. 1989. The tensile strength of cracked ice. Philos. Mag. A, 59(2), 303-311. 
Schulson, E. M., D. E. Jones and G. A. Kuehn. 1991a. The effect of confinement on the brittle compressive fracture of ice. Ann. Glaciol., 15, 216-221.

Schulson, E. M., G. A. Kuehn, D. E. Jones and D. A. Fifolt. 1991b.The growth of wing cracks and the brittle compressive fracture of ice. Acta Metallurgica et Materialia, 39(11), 2651-2655.

Schwarz, J. and W. F. Weeks. 1977. Engineering properties of sea ice. 7. Glaciol., 19(81), 499-531.

Smith, T.R. 1991. The effect of stress state on the brittle compressive failure of columnar ice. (Ph.D. thesis, Dartmouth College.)

Smith, T.R. and E.M. Schulson. 1993. The brittle compressive failure of fresh-water columnar ice under biaxial loading. Acta Metallurgica et Materialia, 41(1), 153-163.
Timco, G.W. and R. Frederking. 1983. Confined compressive strength of sea ice. In POAC 83. The Seventh International Conference on Port and Ocean Engineeering under Arctic Conditions, Helsinki, Finland, 5-9 April 1983. Proceedings. Volume 1. Espoo, Technical Research Centre of Finland, 243-253.

Timco, G.W. and R.M.W. Frederking. 1986. Confined compression tests: outlinng the failure envelope of columnar sea ice. Cold Reg. Sci. Technol., 12(1), 13-28.

Wong, T. -F. 1982. Micromechanics of faulting in Westerly granite. Int. 7. Rock Mech. Min. Sci. Geomech. Abstr., 19, 49-64.

The accuracy of references in the text and in this list is the responsibility of the authors, to whom queries should be addressed.

MS received 26 January 1993 and in revised form 24 June 1993 